\title{
Role of the Suprachiasmatic and Arcuate Nuclei in Diurnal Temperature Regulation in the Rat
}

\author{
Mara Alaide Guzmán-Ruiz, ${ }^{1}$ @Arlen Ramirez-Corona, ${ }^{1}$ Natali Nadia Guerrero-Vargas, ${ }^{1}$ Elizabeth Sabath, ${ }^{1}$ \\ QOscar Daniel Ramirez-Plascencia, ${ }^{1}$ ORebecca Fuentes-Romero, ${ }^{1}$ Luis Abel León-Mercado, ${ }^{1}$ \\ MariCarmen Basualdo Sigales, ${ }^{1}$ Carolina Escobar, ${ }^{2}$ and $@$ Ruud Marinus Buijs ${ }^{1}$ \\ ${ }^{1}$ Instituto de Investigaciones Biomédicas, Universidad Nacional Autónoma de México, Ciudad Universitaria, PC 04510 Mexico D.F., Mexico, and ${ }^{2}$ Facultad \\ de Medicina, Departamento de Anatomía, Universidad Nacional Autónoma de México, Ciudad Universitaria, PC 04510 Mexico D.F., Mexico
}

In mammals, daily changes in body temperature (Tb) depend on the integrity of the suprachiasmatic nucleus (SCN). Fasting influences the $\mathrm{Tb}$ in the resting period and the presence of the SCN is essential for this process. However, the origin of this circadian/metabolic influence is unknown. We hypothesized that, not only the SCN but also the arcuate nucleus (ARC), are involved in the Tb setting through afferents to the thermoregulatory median preoptic nucleus (MnPO). Therefore, we investigated by neuronal tracing and microdialysis experiments the possible targeting of the MnPO by the SCN and the ARC in male Wistar rats. We observed that vasopressin release from the SCN decreases the temperature just before light onset, whereas $\alpha$-melanocyte stimulating hormone release, especially at the end of the dark period, maintains high temperature. Both peptides have opposite effects on the brown adipose tissue activity through thermoregulatory nuclei such as the dorsomedial nucleus of the hypothalamus and the dorsal raphe nucleus. The present study indicates that the coordination between circadian and metabolic signaling within the hypothalamus is essential for an adequate temperature control.

Key words: $\alpha$-melanocyte-stimulating hormone; arcuate; median preoptic nucleus; suprachiasmatic; body temperature; vasopressin

Significance Statement

When circadian and metabolic systems are not well synchronized, individuals may develop metabolic diseases. The underlying mechanisms are unknown. Here, we demonstrate that the balance between the releases of neuropeptides derived from the biological clock and from a metabolic sensory organ as the arcuate nucleus, are essential for an adequate temperature control. These observations show that brain areas involved in circadian and metabolic functions of the body need to interact to produce a coherent arrangement of physiological processes associated with temperature control.

\section{Introduction}

Thermoregulatory processes have a well established brain control center that resides in several nuclei of the hypothalamic preoptic

Received April 13, 2015; revised 0ct. 6, 2015; accepted 0ct. 13, 2015.

Author contributions: M.A.G.-R. and R.M.B. designed research; M.A.G.-R., A.R.-C., N.N.G.-V., E.S., O.D.R.-P. R.F.-R., and M.B.S. performed research; L.A.L.-M. and M.B.S. contributed unpublished reagents/analytic tools; M.A.G.-R., E.S., and M.B.S. analyzed data; M.A.G.-R., C.E., and R.M.B. wrote the paper.

This work was supported by the Dirección General Asuntos del Personal Académico (Grant GAPA IG-200314) and Consejo Nacional de Ciencia y Tecnología (Grant CONACyT 220598). This work comprises a doctoral thesis for the Doctorado en Ciencias Biomédicas from the Universidad Nacional Autónoma de México (UNAM), supported by a CONACyT doctoral student grant. We thank Adrian Baez, Miguel Morales, and Miguel Tapia from the Biomedical Research Institute, UNAM; Marcia Hiriart from the Cellular Physiology Institute, UNAM; and Arina Tamborska from the University of Edinburgh for valuable comments and collaboration; and Leo P. Renaud for critical comments and suggestions.

The authors declare no competing financial interests.

Correspondence should be addressed to Ruud Marinus Buijs, Instituto de Investigaciones Biomédicas, Universidad Nacional Autónoma de México, Av. Universidad 3000, 04510 Mexico D.F., Mexico. E-mail: ruudbuijs@gmail.com.

DOI:10.1523/JNEUROSCI.1449-15.2015

Copyright $\odot 2015$ the authors $\quad 0270-6474 / 15 / 3515419-11 \$ 15.00 / 0$ area where the median preoptic nucleus $(\mathrm{MnPO})$ is the main integration center for thermo-afferents (Romanovsky, 2007; Morrison et al., 2008; Nakamura and Morrison, 2011; Clapham, 2012). In addition to the classic thermoregulatory cues (temperature of skin, temperature of viscera, and proinflammatory signals), the time of day also plays an important role in determining the temperature set point (Eastman et al., 1984; Benstaali et al., 2001; Liu et al., 2002; Scheer et al., 2005). Regardless of locomotor activity, the core body temperature (Tb) increases just before the onset of the animal's active phase and decreases shortly before the beginning of the resting phase (Refinetti and Menaker, 1992b, Scheer et al., 2005). This anticipatory regulation is controlled by the suprachiasmatic nucleus (SCN) in the hypothalamus, which functions as a biological clock and imposes a temporal organization to physiology (Scheer et al., 2005, Liu et al., 2002, Buijs and Kalsbeek, 2001). The circadian control of resting $\mathrm{Tb}$ is also influenced by the feeding status of an animal and a set point 
(amplitude) is established based on the metabolic requirements of an individual.

The influence of both circadian and metabolic systems on $\mathrm{Tb}$ was first revealed by observations that food intake induces a higher thermogenesis during the active phase (Romon et al., 1993; LeBlanc and Soucy, 1996) and that food deprivation induces a $\mathrm{Tb}$ decrease at the beginning of the resting phase. Moreover, SCN lesions prevent, not only circadian but also fastinginduced, Tb changes (Liu et al., 2002; Scheer et al., 2005; Tokizawa et al., 2009). Central mechanisms underlying circadian and metabolic regulation of $\mathrm{Tb}$ are not understood.

Because the SCN induces a circadian rhythm in the activity of the $\alpha$-MSH neurons in the ARC (Saeb-Parsy and Dyball, 2003; Yi et al., 2006; Guzmán-Ruiz et al., 2014), we hypothesized that the $\mathrm{Tb}$ rhythm depends on the interplay between temporal signals from the SCN and metabolic signals from the ARC.

Therefore, we sought to determine whether the ARC, as the main hypothalamic integrator of metabolic information (Williams et al., 2000; Seeley et al., 2004; Cone, 2005; van den Top and Spanswick, 2006), could interact with signals from the SCN at the level of the MnPO and influence the Tb.

We first observed that a single tracer injection into the $\mathrm{MnPO}$ labels both arginine vasopressin (AVP) neurons in the SCN and $\alpha$-melanocyte-stimulating hormone ( $\alpha$-MSH) neurons in the ARC. Next, we demonstrated by means of microdialysis (MD) that the balance between AVP and $\alpha$-MSH release is essential for the induction of the daily $\mathrm{Tb}$ decrease at the beginning of the resting phase.

\section{Materials and Methods}

\section{Experiments}

Experiments were approved by the Committee for Ethical Evaluation at Institute for Biomedical Research, Universidad Nacional Autónoma de México, in accordance with the Mexican norms for animal handling (Norma Oficial Mexicana NOM-062-ZOO-1999). Adult male Wistar rats $(250-280 \mathrm{~g})$ were housed in individual cages under light:dark 12:12 conditions [on: $7 \mathrm{~h}=$ Zeitgeber time (ZT) 0, off: $19 \mathrm{~h}=\mathrm{ZT} 12$ ] and room temperature was maintained within thermoneutrality. Water and regular laboratory rodent diet (Purina Chow 5001) were provided ad libitum.

\section{Tb determination}

To monitor $\mathrm{Tb}$, sterilized temperature sensors (iButton SensorTemperature Logger; Maxim Integrated Products) were inserted intraperitoneally. iButtons collected the temperature data every $10 \mathrm{~min}$ during the experimental procedure. The $\mathrm{Tb}$ change $(\Delta \mathrm{Tb})$ was determined by comparing the baseline $\mathrm{Tb}$ with the $\mathrm{Tb}$ during the experimental procedure. The baseline $\mathrm{Tb}$ was calculated as the mean $\mathrm{Tb}$ within $1 \mathrm{~h}$ before the experiments.

\section{Stereotactic surgery for the placement of CtB tracer or MD probes in the $\mathrm{MnPO}$}

Rats $(n=12)$ were injected with $0.1 \mu \mathrm{l}$ of the retrograde tracer Cholera toxin $\mathrm{B}$ (CtB) $0.25 \%$ conjugated with the Alexa Fluor-555 fluorescent dye (Invitrogen). Of a total of 12 rats, six were correctly injected in the MnPO.

MD probes were constructed according to the procedures described previously (Kalsbeek et al., 1995) and implanted adjacent to the MnPO to avoid lesions within the nucleus (stereotactic coordinates: $+0.3 \mathrm{~mm}$ anterior from bregma; $\pm 0.11 \mathrm{~mm}$ lateral from midline; $-5.4 \mathrm{~mm}$ ventral from the cortex). After the implantation, the MD probes were filled with Ringer's solution ( $\mathrm{NaCl} 0.85 \%, \mathrm{KCl} 0.04 \%, \mathrm{CaCl}_{2} 0.034 \%$, Milli $\mathrm{Q} \mathrm{H}_{2} \mathrm{O}$ ). The experiments were performed $7 \mathrm{~d}$ after the surgery in the animal's home cage.

Of a total of 68 animals implanted with MD probes, 38 were included in the present study. The reasons for exclusion were as follows: incorrect probe placement $(n=15)$, MD probe blockage $(n=12)$, and animal death after the surgery $(n=3)$.

\section{Immunohistochemistry}

All rats were deeply anesthetized with a lethal dose of sodium pentobarbital and perfused transcardially with $0.9 \%$ saline solution followed by paraformaldehyde $4 \%$ in $0.1 \mathrm{M}$ PBS, pH 7.4. Brains were removed and kept in fixative at $4^{\circ} \mathrm{C}$ overnight, followed by $48 \mathrm{~h}$ in a $30 \%$ sucrose solution. Then, $40 \mu \mathrm{m}$ coronal sections were collected into RNAase-free $0.1 \mathrm{M}$ PBS and used for Nissl staining, immune labeling, or in situ hybridization. The protocol for immunohistochemistry was performed as described in Guzmán-Ruiz et al. (2014).

To determine the $\mathrm{CtB}$ injection site, $\mathrm{MnPO}$ sections (two anterior, two medial, and two posterior) from CtB-injected animals were incubated with rabbit anti-CtB primary antibody 1:4000 (Calbiochem), biotinylated donkey anti-rabbit serum 1:400 (Jackson Laboratories), and avidinbiotin complex 1:500 (Vector Laboratories). The reaction product was visualized by incubation for $6 \mathrm{~min}$ in Ni-intensified $\mathrm{DAB}+\mathrm{H}_{2} \mathrm{O}_{2}$ solution $(0.01 \%$ diamino benzidine, $0.01 \%$ hydrogen peroxide, and $0.05 \%$ nickel ammonium sulfate).

To determine the identity of the neurons traced with $\mathrm{CtB}, \mathrm{SCN}$ and $\mathrm{ARC}$ sections were incubated either with the primary antibody against rabbit AVP 1:2000 (Buijs et al., 1989) or with sheep $\alpha$-MSH polyclonal antibody 1:1600 (Millipore). The secondary antibodies were $\mathrm{Cy}$ 2-conjugated affinitypurified donkey anti-rabbit or anti-sheep secondary antibodies 1:400 (Jackson Laboratories). The sections were analyzed with the Laser Scanning Microscope 5 Pascal confocal microscope (Zeiss).

To determine the position of the MD cannula, 3 sections of the MnPO (anterior, medial, and posterior) were stained with cresyl violet $1 \%$.

In addition, immunohistochemistry was performed on the MnPO sections of the light-exposed rats (four/rat) and the dorsomedial nucleus (DMH, four/rat) and rostral raphe nucleus (four/rat) sections of the MD-treated rats. The sections were incubated with rabbit anti-c-FOS primary antibody (1:40,000; Calbiochem) followed by biotinylated donkey anti-rabbit serum 1:400 (Jackson Laboratories), avidin-biotin incubations, and visualized with DAB. c-FOS quantification was performed by obtaining the mean of the four sections of each brain.

\section{In situ hybridization}

Four to six MnPO sections were selected from intact brains $(n=6)$ and treated for in situ hybridization as described previously (Zaidi et al., 2000). The sections were incubated with RNA probes for Gad65 and visualized with streptavidin-Cy 3. Subsequent immunohistochemistry was performed using either rabbit anti-AVP or sheep anti- $\alpha$-MSH primary antibodies and visualized with donkey anti-rabbit or donkey antisheep conjugated with Cy 2 as described above.

The presence of GABAergic neurons associated with AVP or $\alpha$-MSH fibers in the MnPO was determined by the proximity of GAD65-positive neurons with AVP or $\alpha$-MSH fibers. The cutoff distance in dorsal ventral direction was $1 \mu \mathrm{m}$ as determined by the opening of the confocal pinhole. When fibers were $>1 \mu \mathrm{m}$ distant from the cell body in lateral direction, they were considered not in contact.

\section{BAT q-PCR}

Total RNA was extracted from brown adipose tissue (BAT) using TRIzol reagent (Life Technologies). Total RNA (2500 ng) was reversely transcribed to single-strand cDNA using the SuperScript III first-strand synthesis kit (Invitrogen). For relative quantification by real-time PCR (q-PCR), $50 \mathrm{ng}$ of the first-strand cDNA sample was mixed with $5 \mu \mathrm{l}$ of Master Mix Sybr select master mix (Applied Biosystems), $2 \mu$ l of Milli-Q water, and $1 \mu \mathrm{l}$ of a primer mixture containing $10 \mathrm{~mm}$ hypoxanthine guanine phosphoribosyl transferase (Hprt) Fwd 5'-ACATTGTGGCC CTCTGTGTG-3', Rev 5'-GGGCTGTACTGCTTGACCAA-3', reverseerytroblastosis virus $\alpha$ nuclear receptor $\left(\operatorname{Rev}\right.$-erb- $\alpha$ ) Fwd $5^{\prime}$-TAAAGT GTGTGGGGACGTGG-3' ${ }^{\prime}$, Rev $5^{\prime}$-TGCCAACGGAGAGACACTTC- ${ }^{\prime}$, Ucp1 Fwd 5'-GCCGGCGATCCGGGCTTAAA-3', Rev 5'-GGCTCG GAGGGCAGAGACCA-3') (Turek et al., 2009). An ABI Prism 7000 Sequence Detection System (Applied Biosystems) was used to amplify the genes from each BAT sample in triplicate on a 96-well reaction plate. The relative amount of mRNA was calculated by using the $\Delta \Delta \mathrm{Ct}$ method with an efficiency adjustment according to the equation by Pfaffl (2001). The Hprt gene was used as an endogenous control for data normalization. 
A

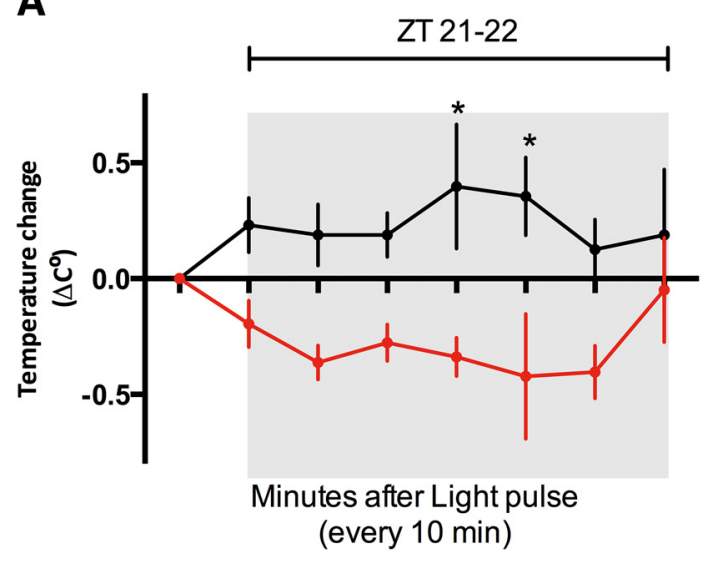

B

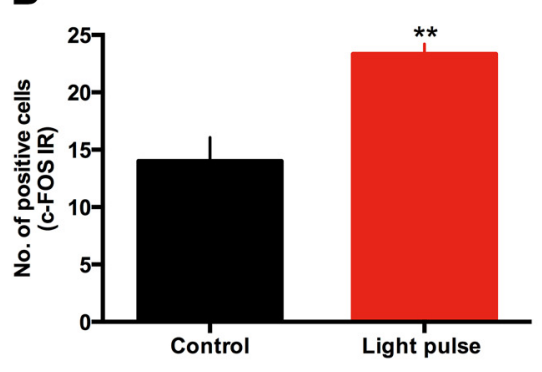

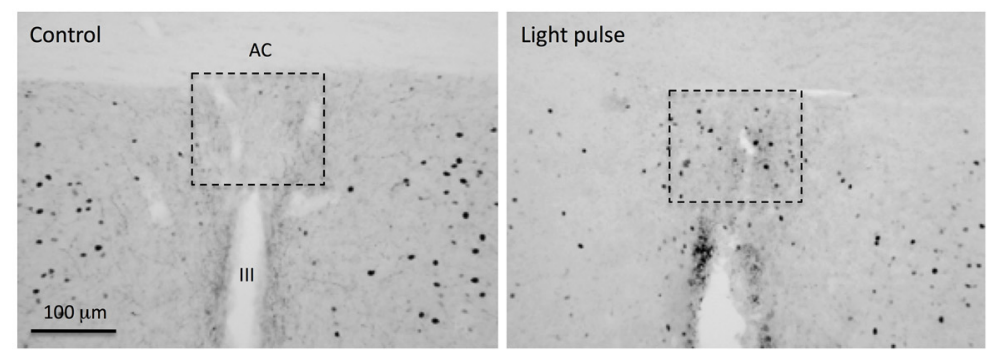

Figure 1. Light decreases core temperature and increases c-FOS expression in the MnP0. $A$, Tb change in animals that received a light pulse during the night from ZT $21-22(n=3)$ compared with the control animals $(n=3)$. Significance differences between the two groups are indicated. ${ }^{*} p<0.05$. B, Number of c-FOS expressing cells in the MnP0 in response to light and representative sections of the MnPO c-FOS-IR (dashed rectangles) during the dark phase at ZT 22. ${ }^{* *} p=0.0073$. AC, Anterior commissure; III, third ventricle.

\section{Experimental procedures}

Experiment 1: neuronal activity of the $M n P O$ in response to a light pulse during the night. Rats $(n=6)$ were implanted intraperitoneally with temperature probes (no other surgery). After $5 \mathrm{~d}$ of recovery, the animals were separated into two groups. The control group $(n=3)$ was kept under normal lightdark conditions and the experimental group $(n=3)$ received a 1-h-long light pulse (LP) during the last part of the dark phase (ZT 21-22) The light intensity of this LP was the same as during the light period (250 lux). Both groups were anesthetized and perfused transcardially at ZT 22 . The intraperitoneal temperature buttons were collected and the brains were processed for c-FOS immunohistochemistry of the MnPO.

Experiment 2: determination of MnPO afferents. Rats $(n=12)$ were injected with $\mathrm{CtB}$ in the $\mathrm{MnPO}$ and left without any other manipulation for $7 \mathrm{~d}$ to allow transport of the tracer. After this time, animals were deeply anesthetized and then perfused transcardially with fixative and their brains were processed for confocal microscopy.

Experiment 3: functional determination of the role of $\alpha-M S H$ and AVP signals in the MnPO. MD experiments were conducted $7 \mathrm{~d}$ after insertion of the MD probes into the $\mathrm{MnPO}$ and temperature iButtons into the peritoneal cavity. Two time points were selected for the MD protocols (see Fig. $3 F$ ).

The MD probes were connected to the syringes containing the Ringer's solution $12 \mathrm{~h}$ before the experiment; the tubes were attached to swivels to allow the animals free movement. The syringes were attached to the infusion pump.

The experimental setups for each of the MD infusions were as follows: For the beginning of the light phase, $2 \mathrm{~h}$ Ringer's infusion was started at ZT 0 (perfusion rate: $3 \mu \mathrm{l} / \mathrm{min}$ ) to ensure the stabilization of the $\mathrm{Tb}$ for all groups. After $2 \mathrm{~h}$ of Ringer infusion, the syringe was exchanged at ZT 2 and for the next $3 \mathrm{~h}$ (ZT 2-5), one of the following substances was infused: (1) melanotan II acetate salt (MTII) (Sigma-Aldrich), a MC3-4R agonist (5 ng/ $\mu \mathrm{l}$, perfusion rate; $3 \mu \mathrm{l} / \mathrm{min}, n=4)$; (2) [Deamino-Pen ${ }^{1}, O-M e r-T y r^{2}$, $\mathrm{Arg}^{8}$ ]-Vasopressin (V1A-ant) (Sigma-Aldrich), a V1A receptor antagonist (Vla-ANT, $2.5 \mathrm{ng} / \mu \mathrm{l}$, perfusion rate; $3 \mu \mathrm{l} / \mathrm{min}, n=4$ ); or (3) $\mathrm{VlaANT}+\mathrm{MTII}(5 \mathrm{ng} / \mu \mathrm{l}$ and $2.5 \mathrm{ng} / \mu \mathrm{l}$ respectively, perfusion rate; $3 \mu \mathrm{l} /$ $\min , n=5$ ). After the infusion of the respective drugs, the syringe was exchanged again to Ringer's solution for $2 \mathrm{~h}$ with the exception of 3 rats that received V1aANT+ MTII or Ringer's. These rats were killed at the end of the infusion for brain and BAT collection.

For the end end of the dark phase, Ringer's perfusion (perfusion rate: $3 \mu \mathrm{l} / \mathrm{min}$ ) was performed from (ZT 16-18) to ensure the stabilization of the $\mathrm{Tb}$ for all groups. After $2 \mathrm{~h}$ of Ringer infusion, the syringe was ex- changed at ZT 18 and for the next $3 \mathrm{~h}$ (ZT 18-21) one of the following substances was infused: (1) $\left[\operatorname{Arg}^{8}\right]$-AVP (Sigma-Aldrich) $(5 \mathrm{ng} / \mu \mathrm{l}$, perfusion rate; $3 \mu \mathrm{l} / \mathrm{min}, n=4)$; (2) acetyl- $\left[\mathrm{Nle}^{4}, \mathrm{Asp}^{5}, \mathrm{D}-2-\mathrm{Nal}^{7}\right.$, Lys $\left.{ }^{10}\right]$ cyclo- $\alpha$-MSH (SHU9119), an MC3-4 antagonist (5 ng/ $\mu$ l, perfusion rate; $3 \mu \mathrm{l} / \mathrm{min}, n=6$ ) for $2 \mathrm{~h}$; or (3) VlaANT+SHU9119 (5 ng/ $\mu \mathrm{l}$, perfusion rate; $3 \mu \mathrm{l} / \mathrm{min}, n=4)$. After the infusion of the respective drugs, the syringe was exchanged again to Ringer's solution for $2 \mathrm{~h}$ with the exception of 3 rats that received SHU9119 or Ringer's. These rats were killed at the end of the infusion for brain and BAT collection.

The same protocol was performed in the control group, including exchanging syringes, but instead of agonist or antagonist, Ringer's solution was infused for the entire experiment (ZT 2-5, $n=5$; ZT 18-21, $n=7$ ). The dead space between the fluid swivel and dialysis membrane was $40-50 \mu \mathrm{l}$. Therefore, dialysate containing the respective drug reached the membrane within 15-20 min after the syringe exchange and this time was taken into account in all of the analyses.

\section{Activation of pre-autonomic outputs and peripheral} thermo-effectors

The neuronal activity pattern of pre-autonomic nuclei was determined by means of c-FOS IR in the DMH and the Raphe. For this purpose, the animals were killed immediately after: Ringer's ZT $2-5(n=3)$, Ringer's ZT 18-21 $(n=3)$, V1Aant+ MTII $(n=3)$, or SHU9119 $(n=3) \mathrm{MD}$ infusions. The interescapular brown adipose tissue was also obtained for Ucp1 and Rev-erb $\alpha$ gene expression to investigate the possible downstream mechanisms of the observed temperature changes.

\section{Statistical analysis}

c-FOS expression in the $\mathrm{MnPO}$ in response to the light pulse was compared with a nonpaired $t$ test. A non-repeated-measures one-way ANOVAs and Tukey's post hoc tests were used to compare the c-FOS expression in the MD-treated animals. Ucp 1 and Rev-erb $\alpha$ gene expression was compared with a nonpaired $t$ test. The analysis of the Tb curves was performed with a non-repeated-measures two-way ANOVA, followed by Bonferrioni's or Dunnett's post hoc test if significant. The differences were considered significant if $p<0.05$. Results are expressed as mean \pm SEM.

\section{Results}

Median preoptic nucleus responds to light

Light exposure, especially at the end of the dark period, decreases Tb (Scheer et al., 2005). To investigate whether the MnPO re- 

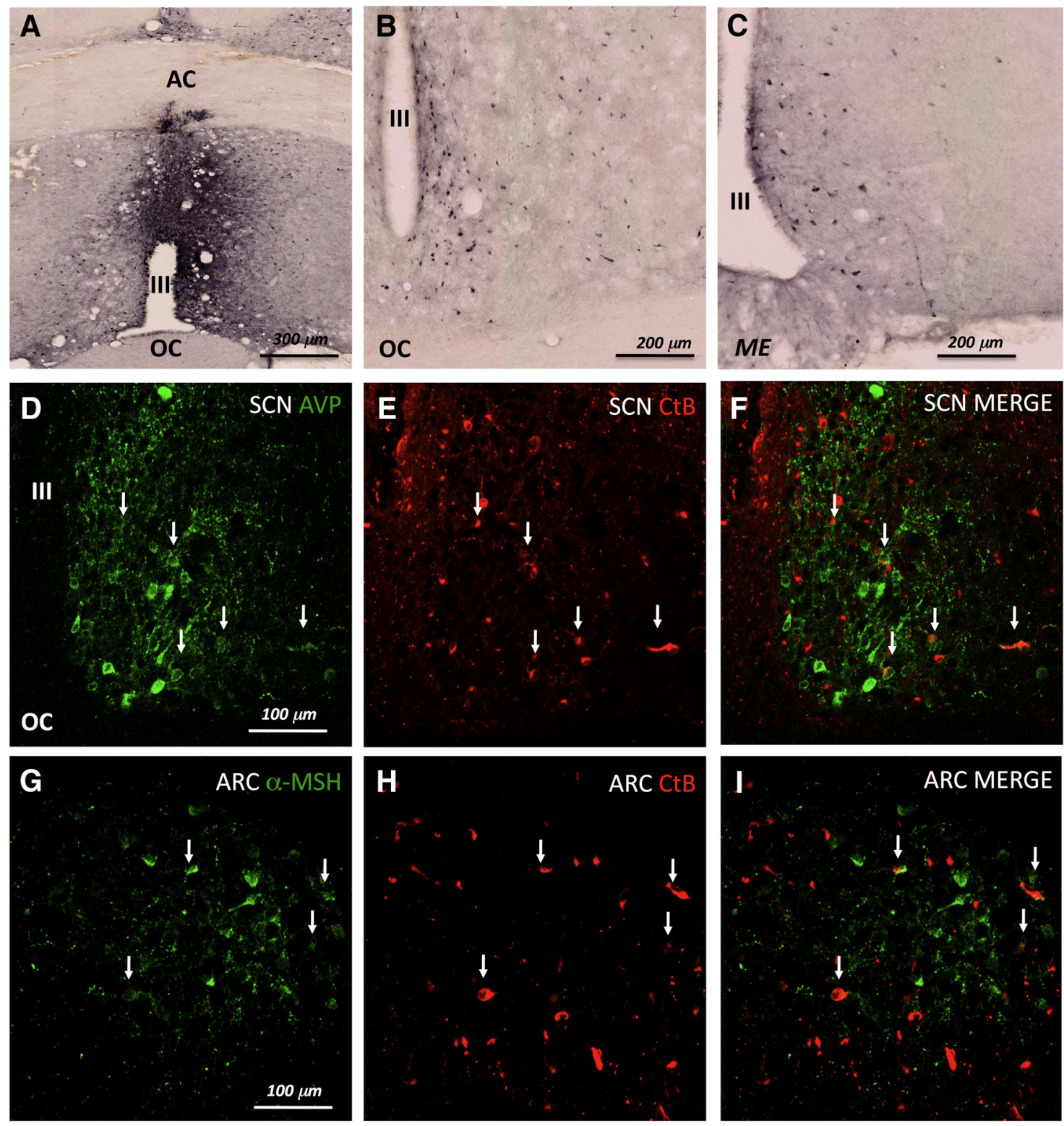

Figure 2. CtB injections in the $\mathrm{MnPO}$ result in retrograde filled neurons in ARC and SCN. A, A correct injection site in the ventral MnPO. B, Retrograde tracing to the SCN. C, Retrograde tracing to the ARC. D, AVP neurons immunoreactivity (IR) in the SCN in green. $\boldsymbol{E}$, CtB retrograde tracing from the MnPO to the SCN in red. $\boldsymbol{F}$, Merge demonstrating the colocalization between AVP and CtB. $\boldsymbol{G}$, $\alpha$-MSH neurons IR in the ARC in green. $\boldsymbol{H}$, CtB retrograde tracing from the MnPO to the ARC. I, Merge demonstrating the colocalization between $\alpha$-MSH and CtB. AC, Anterior commissure; $0 C$, optic chiasm; III, third ventricle; ME, median eminence.

sponds to a photic stimulus and thus could be responsive to SCN input, rats were subjected to a $1 \mathrm{~h}$ light pulse during the night (ZT 21-22) under ad libitum conditions. We observed that nighttime light exposure decreased $\mathrm{Tb}$ compared with the nonexposed rats $\left(F_{(1,32)}=34.42, p<0.0001\right.$; Fig. $\left.1 A\right)$. In addition, this photic stimulus promotes an increase in c-FOS expression in the $\mathrm{MnPO}$ $\left(t_{(4)}=4.128 ; p=0.0073\right.$; Fig. $\left.1 B\right)$, indicating that this nucleus is responsive to photic stimuli.

\section{Retrograde tracing from the MnPO}

To determine the neuronal afferents in the $\mathrm{MnPO}$ area that respond to light, injections of the retrograde tracer $\mathrm{CtB}$ were given into the MnPO. The injection site was considered correct when the $\mathrm{CtB}$ was distributed only within the MnPO limits (Fig. 2A).

Successful injections into the $\mathrm{MnPO}$ always resulted in retrogradely labeled neurons both in the SCN and in the ARC (Fig.
$2 B, C)$. SCN neurons projecting to the $\mathrm{MnPO}$ were identified as AVP containing (Fig. $2 D-F$ ), whereas ARC neurons were identified as $\alpha$-MSH containing (Fig. $2 G-I$ ).

In addition to the $\mathrm{SCN}$ and the ARC neurons projecting to the $\mathrm{MnPO}$, we also found $\mathrm{CtB}$ in somas of the bed nucleus of the stria terminalis (BNST), above the supraoptic nucleus (SON), in the subparaventricular zone and in the DMH (data not shown). We did not determine the peptides involved in the signaling of these nuclei to the $\mathrm{MnPO}$. However, we established that the AVP-producing cells of the BNST and the PVN do not project to the MnPO, so the AVP supply to the $\mathrm{MnPO}$ is provided only by the $\mathrm{SCN}$.

We also investigated whether other neuronal populations within the SCN and the ARC colocalize with $\mathrm{CtB}$ from the injections into the MnPO. No CtB-containing neurons in the SCN expressed vasointestinal peptide.

Within the ARC, no colocalization was observed with neurons 
X Misplacements

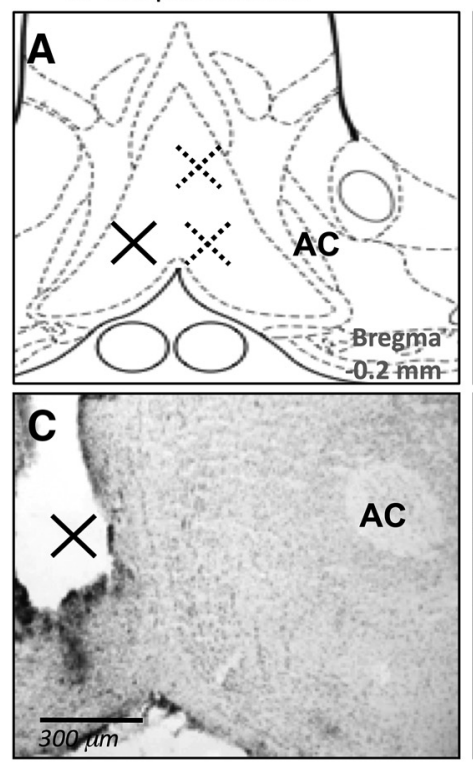

Correct placements
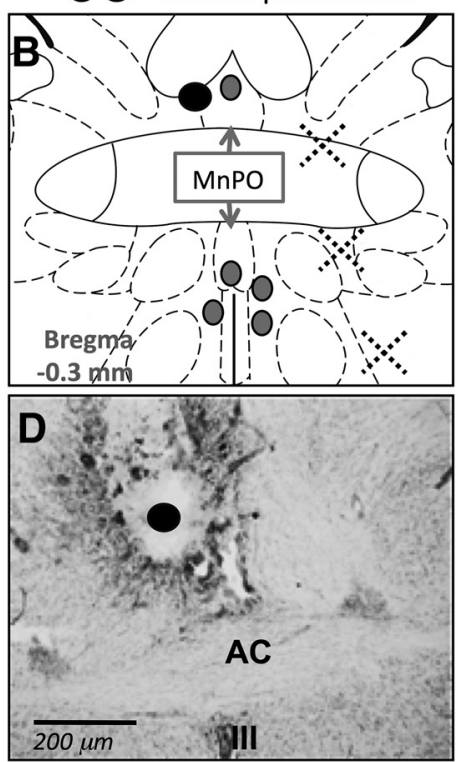
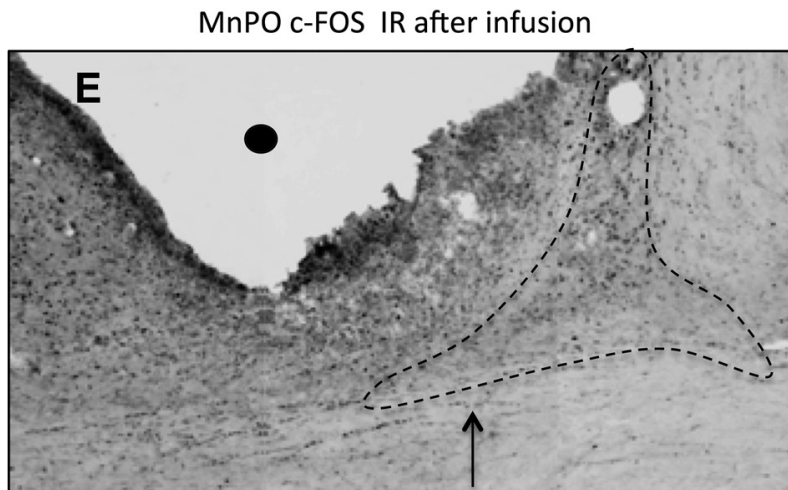

AC

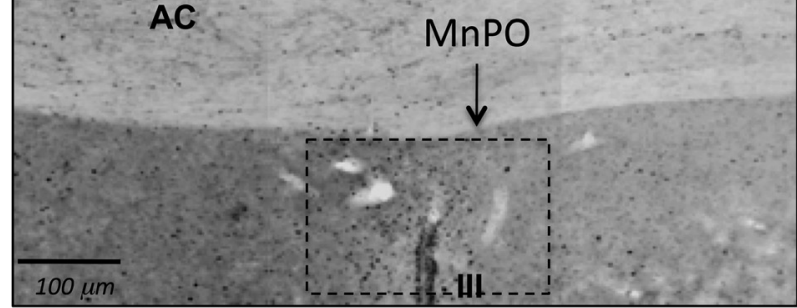

$\mathbf{F}$

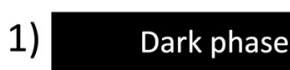

ine

2)

Dark phase

\begin{tabular}{|lr|}
\multicolumn{2}{c|}{ 2 h Ringer } \\
\hline ZT 0 & ZT 2 \\
\hline ZT 16 & ZT 18
\end{tabular}

$3 \mathrm{~h}$ Drug

ZT 5

ZT 21

Light phase

Figure 3. Correct and incorrect MD cannula placement in the MnP0. Shown are Paxinos schemes $(\boldsymbol{A}, \boldsymbol{B})$ and Nissl staining $(\boldsymbol{C}, \boldsymbol{D})$ for determination of cannula placement. The sites where the infusion had an effect on $\operatorname{Tb}(\bullet, O)$ and the areas where probe placements did not have any effect on temperature $(X)$ are indicated in the schemes from Paxinos rat brain atlas. $E, c-F 0 S-I R$ of a correct MD cannula placement $(\bullet, 0)$ after V1Aant infusion. $\boldsymbol{F}$, Time points when infusions were done; black bars indicate the dark phase and the white bar indicates the light phase; (1) indicates the day experimental setup and (2) the night experimental setup as described in the experimental procedures. AC, Anterior commissure; $O C$, optic chiasm.

expressing cocaine amphetamine related transcript, whereas colocalization with NPY neurons could not be established because of the low staining intensity of those neurons.

In this research, we focused our further analysis on those neuronal populations in which a circadian rhythm has been demonstrated that colocalized with $\mathrm{CtB}$; that is, AVP and $\alpha$-MSH neurons.

\section{$\alpha$-MSH signaling in the MnPO increases $\mathrm{Tb}$}

Vasopressin neurons of the SCN and $\alpha$-MSH neurons of the ARC have a clear circadian rhythm (Schwartz et al., 1983; Kalsbeek et al., 1995; Guzmán-Ruiz et al., 2014). $\alpha$-MSH neuronal activity is especially high at the end of the dark phase and low at the beginning of the light period (Guzmán-Ruiz et al., 2014). Therefore, we first examined the effect of the infusion of an MC3-4 receptor agonist, MTII, in the MnPO early in the light phase with the hypothesis that this would prevent the decrease in temperature observed during the day.

Only the animals that had a correct placement of the MD probe were taken into account (Fig. $3 A-D$ ). To ensure that the $\mathrm{MD}$ probe did not damage the MnPO, we determined, not only its position, but also the neuronal activation in the MnPO by means of c-FOS-IR (Fig. 3E).

MTII infusions into the MnPO prevented the diurnal drop in $\mathrm{Tb}$ compared with the Ringer-infused rats that showed a significant $\mathrm{Tb}$ decrease associated with the onset of light $\left(F_{(1,166)}=66.35, p<\right.$ 0.0001 , Fig. 4A). Importantly, the MTII infusion did not increase the $\mathrm{Tb}$, instead, the Tb maintained the baseline levels.

Next, we hypothesized that the nocturnal peak in $\alpha$-MSH neuronal activity keeps the Tb high via release of $\alpha-\mathrm{MSH}$ in the MnPO. Therefore, we investigated the effect of acetyl-[Nle ${ }^{4}$,
Asp $^{5}, \mathrm{D}-2-\mathrm{Nal}^{7}$, Lys $^{10}$ ]-cyclo- $\alpha$-MSH (SHU9119), a MC3-4R antagonist, on $\mathrm{Tb}$ during the night.

Infusion of SHU9119 from ZT 18 to 20.3, during the reported activity peak of the $\alpha$-MSH neurons, induced a significant decrease in Tb after an $\mathrm{h}\left(F_{(1,240)}=76.21, p<0.0001\right.$, Fig. $\left.4 B\right)$. This $\mathrm{Tb}$ decrease was so rapid and profound that the infusion needed to be terminated $40 \mathrm{~min}$ before the anticipated time to allow the animals to recover from the induced hypothermia.

\section{AVP signaling in the MnPO decreases $\mathrm{Tb}$}

AVP secretion from the SCN has a diurnal pattern and it starts to increase at the end of the dark phase. It reaches its peak during the light period (Schwartz et al., 1983; Kalsbeek et al., 1995), which coincides with the diurnal Tb decrease. To determine whether AVP has a hypothermic effect, we infused AVP into the MnPO during the end of the dark phase (ZT $18-21)$ when $\mathrm{Tb}$ is high.

In the second half of the dark phase, AVP infusion resulted in a significant $\mathrm{Tb}$ decrease compared with Ringer infusion $\left(F_{(1,208)}\right.$ $=202.65, p<0.0001$; Fig. $4 C)$. When the same infusion was performed at the beginning of the light phase (ZT 2-4), such a profound hypothermia was observed that one animal died and only switching to Ringer's infusion reverted the hypothermic state of the other animal. Therefore, no further experiments were performed using AVP at this time point (data not shown). These observations suggest that AVP in the MnPO is involved in the diurnal temperature decrease. To confirm this hypothesis, we infused an antagonist of the V1a receptor [deamino-Pen ${ }^{1}$, O-Mer-Tyr ${ }^{2}$, Arg $\left.^{8}\right]$-Vasopressin (V1a-ANT), into the MnPO 

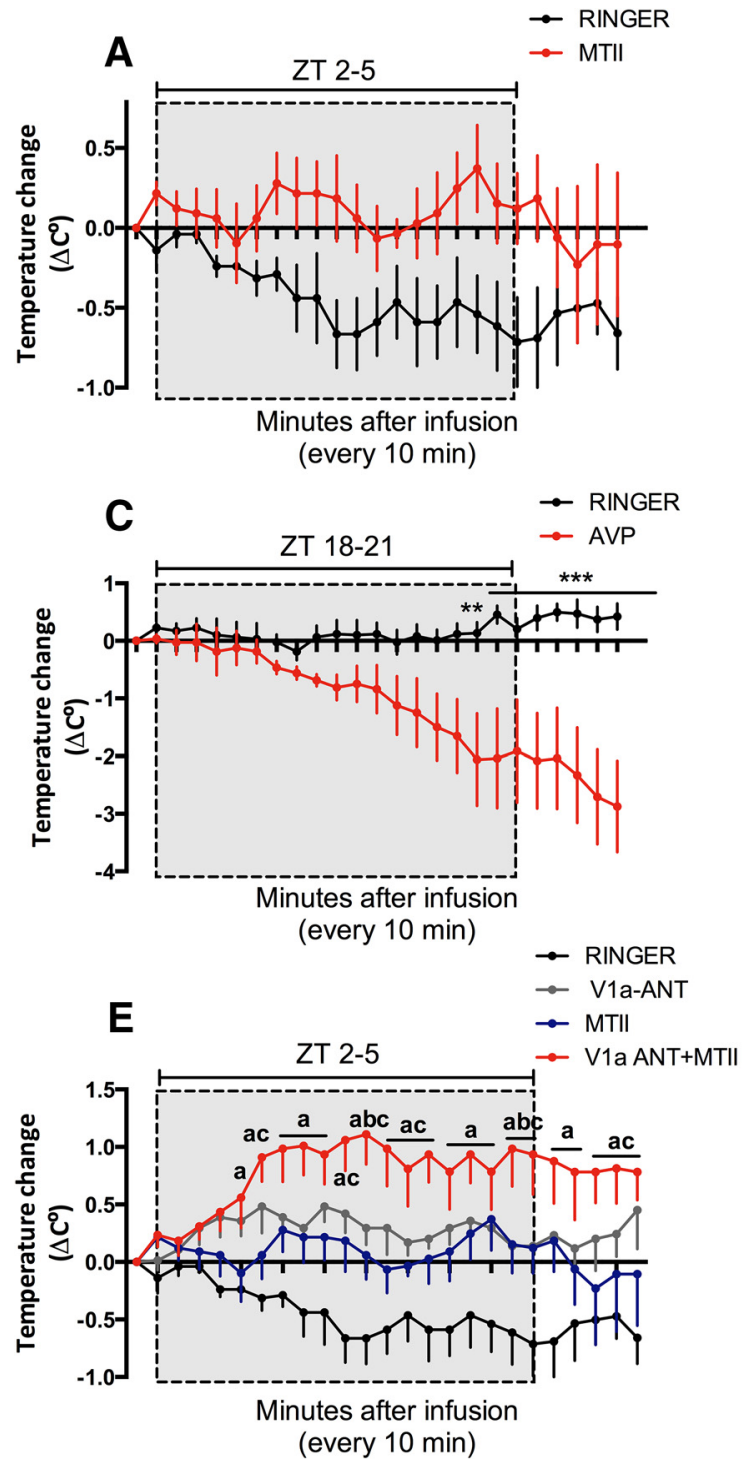
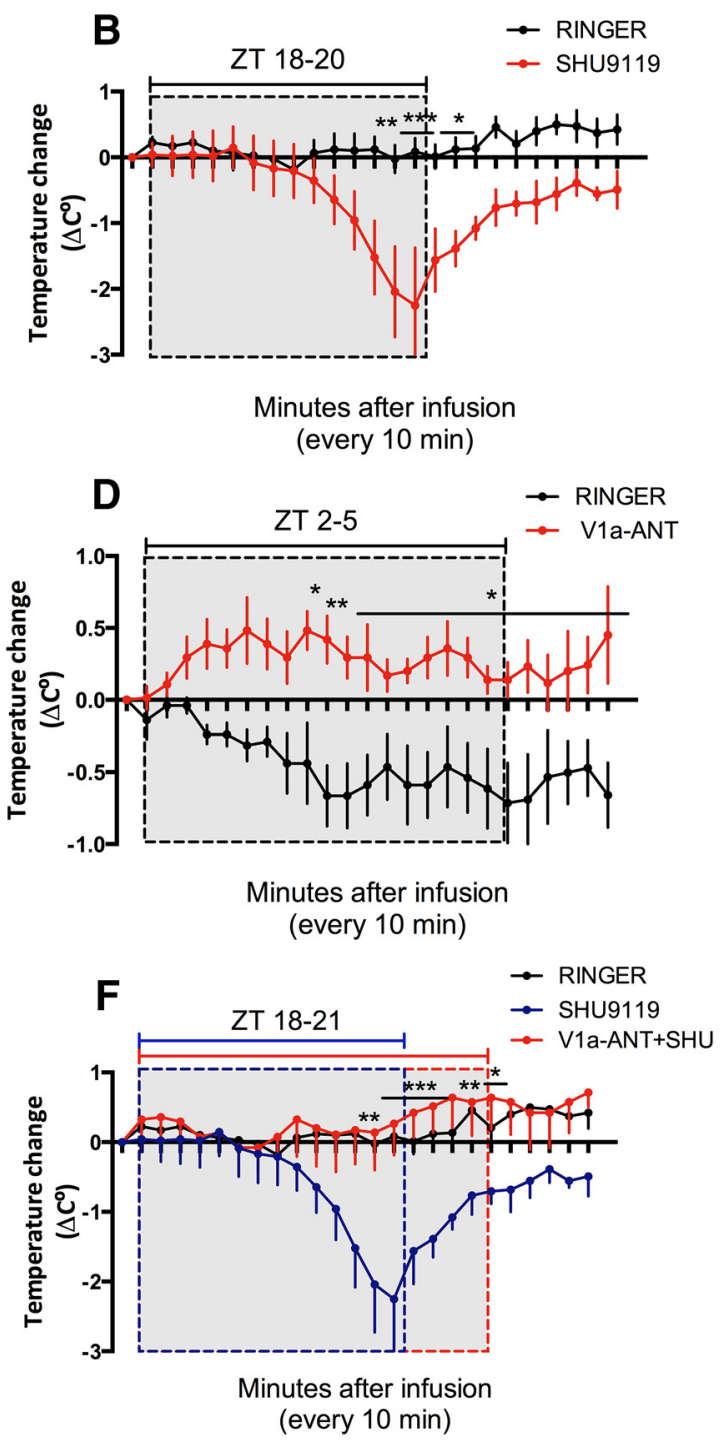

Figure 4. Balance between AVP and $\alpha$-MSH in the MnPO determines the Tb. Change in core temperature of animals infused into the MnPO with $(\boldsymbol{A}) \mathrm{MTII}(n=4)$ versus Ringer $(n=5)$ at ZT 2-5 (B) SHU9119 $(n=6)$ versus Ringer $(n=7)$ at ZT 18-20.3, (C) AVP $(n=4)$ versus Ringer $(n=7)$ at ZT 18-21, (D) V1a-ANT $(n=4)$ versus Ringer $(n=5)$ at ZT 2-5. Significant differences are indicated by Bonferroni's post hoc for individual time points are indicated with an asterisk. $E$, Simultaneous infusion of V1a-ANT + MTII $(n=5)$ at ZT $2(n=5)$ compared with the respective single infusions. Significant differences between V1a-ANT+MTII versus Ringer are represented as $a$, between V1a-ANT+MTII versus MTII are noted as $b$, and between V1a-ANT + MTII versus V1a-ANT as c. $\boldsymbol{F}$, Simultaneous infusion of V1a-ANT + SHU9119 at ZT $18(n=4)$ compared with the SHU9119 single infusion. Significant differences between V1a-ANT + SHU9119 vs SHU9119 are indicated with an asterisk. No significant differences between V1a-ANT + SHU9119 versus Ringer were found. Temperature data were collected every $10 \mathrm{~min}$. Dotted rectangles indicate the infusion period, the blue dotted box indicates SHU9119 infusion period, and the red dotted box indicates V1a-ANT + SHU9119. ${ }^{*} p<0.05,{ }^{* *} p<0.01,{ }^{* * *} p<0.0001$.

during the first part of the light phase when the diurnal Tb decreases and AVP is secreted from the SCN.

Blocking the V1a receptors in the MnPO maintained a higher temperature during the light phase (ZT 2-5) compared with Ringer's infusion at the same time point $\left(F_{(1,66)}=159.55, p<\right.$ 0.0001 ; Fig. $4 D$ ). The same experiment was performed during the dark phase from ZT 18 to 21, which is before the onset of the AVP release (Schwartz et al., 1983). No significant effect of the V1aANT infusion on $\mathrm{Tb}$ during the night was observed $\left(F_{(1,179)}=\right.$ $1.78, p=0.9012$, data not shown).

\section{Balance between AVP and $\alpha$-MSH release in the MnPO} determines diurnal $\mathrm{Tb}$

The onset of the light phase is characterized by a steep $\mathrm{Tb}$ decrease starting at ZT 0 and continuing until ZT 4, which suggests the inhibition of the $\alpha$-MSH input into the MnPO. This was indeed indicated by the infusion of MTII (Fig. 4A) that prevented the temperature decrease during the day. Next, we hypothesized that the presence of AVP during the day prevents the thermogenic effects of MTII. The infusion of the V1a-ANT together with MTII confirmed this hypothesis because the combination of these compounds resulted in a significant increase in $\mathrm{Tb}$ compared with the Ringer's or the single infusion of V1a-ANT or MTII $\left(F_{(3,332)}=126.67 p<0.0001\right.$; Fig. $\left.4 E\right)$. Dunnett's comparison of the V1aANT and MTII curves versus the V1a-ANT+MTII curve demonstrates that the AVP signal to the MnPO needs to be inhibited to allow $\alpha$-MSH to induce a Tb increase. Therefore, the lack of temperature increase at ZT 2-4 using MTII alone was due to the presence of diurnal AVP secreted by the SCN, which prevents thermogenesis. 

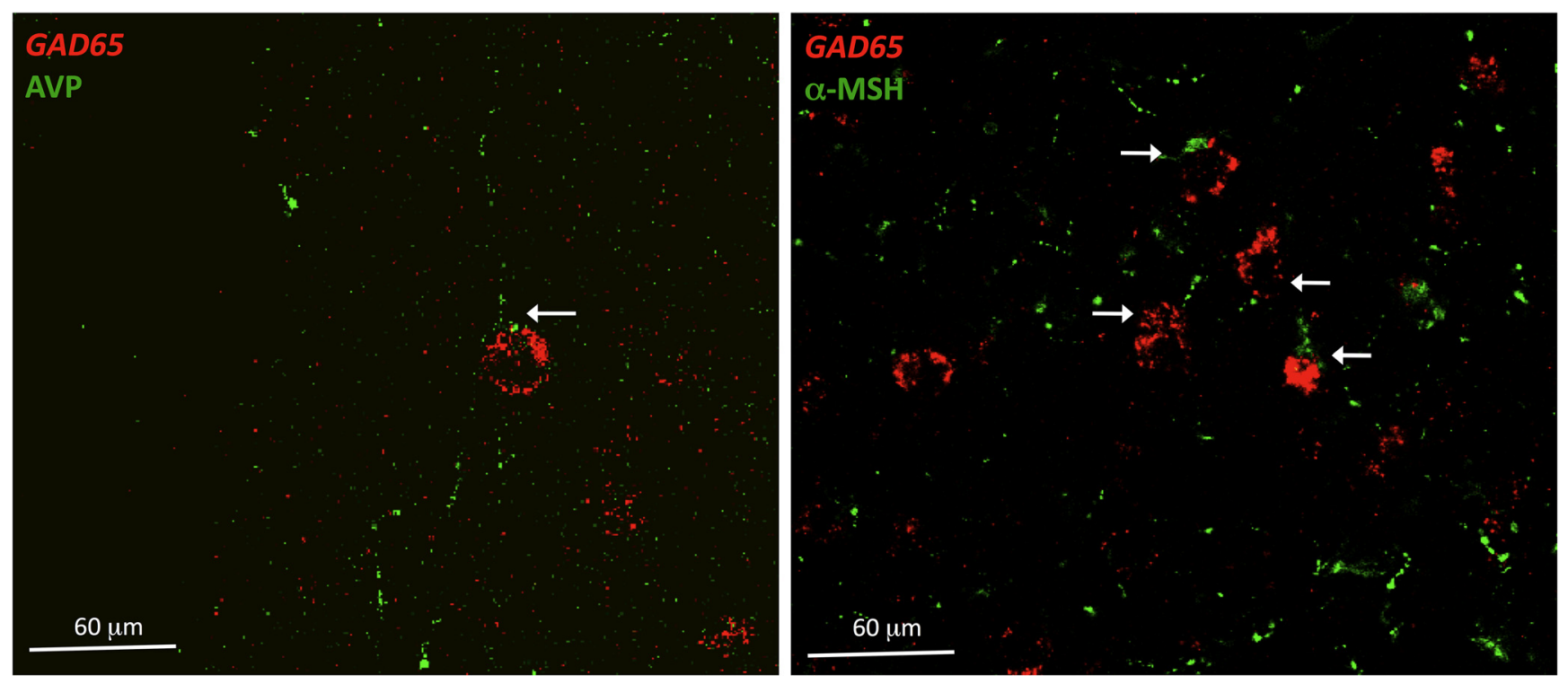

Figure 5. AVP and $\alpha$-MSH fibers contact GABA-ergic neurons in the MnP0. Shown is in situ hybridization for Gad 65-expressing neurons (red) and AVP-or $\alpha$-MSH-immunoreactive fibers (green) in the $\mathrm{MnPO}$. Arrows indicate close association between fibers and somas.

Because the hypothermia induced by blocking the $\alpha$-MSH receptors becomes evident only after $1 \mathrm{~h}$ (ZT 19), we hypothesized that an additional signal is needed for activating heat loss mechanisms at that time (Fig. 4B).

Based on the observed hypothermic effects of AVP in our previous experiment, we inferred that endogenous AVP release is responsible for the Tb decrease followed by blocking $\alpha$-MSH receptors. To test this hypothesis, we antagonized V1a and MC3-4R receptors during the last part of the dark phase.

We observed that the SHU9119-mediated Tb decrease is completely prevented when the AVP signal is also blocked, significant differences in the drug effects and their onset of action were detected $\left(F_{(48,314)}=1.590, p=0.01 ;\right.$ Fig. $\left.4 F\right)$. Dunnett's post hoc tests showed significant differences between the Tb of the VlaANT + SHU9119- versus SHU9119- infused animals, but not between the Ringer's- versus SHU9119-infused rats. This demonstrates that the balance between AVP and $\alpha$-MSH release determines the $\mathrm{Tb}$ decrease at the end of the dark phase.

\section{AVP and $\alpha$-MSH signal to GABAergic neurons in the MnPO}

The MnPO contains GABAergic neurons that receive sensory information about the ambient temperature and the $\mathrm{Tb}$. These neurons project to other thermoregulatory nuclei to modulate thermoeffectors in the periphery (Nakamura and Morrison, 2011).

To investigate whether AVP and $\alpha$-MSH interact with these GABAergic neurons, we performed in situ hybridization for GAD 65 and immunohistochemistry for AVP or $\alpha$-MSH fibers in the $\mathrm{MnPO}$ (Fig. 5).

We observed that GAD65-expressing neurons in the MnPO were associated with both, AVP $(24 \%, \pm 4.33$ SEM $)$ and $\alpha$-MSH terminals $(65 \%, \pm 4.36 \mathrm{SEM})$. We did not observe AVP or $\alpha$-MSH fibers in the zone containing glutamatergic neurons.

AVP and $\alpha$-MSH signals in the MnPO activate pre-autonomic outputs and peripheral thermo-effectors

To investigate the possible thermoregulatory pathways used by the MnPO to increase the temperature after V1Aant+MTII or to decrease the temperature after SHU9119 infusion, we quantified the neuronal activation by means of c-FOS expression in the $\mathrm{DMH}$ and the raphe, two nuclei known to be involved in the thermoregulatory output.

The DMH showed significant activation in response to the V1a-ANT+MTII thermogenic infusion compared with Ringer's $\left(F_{(3,8)}=25.55, p=0.0002\right.$, multiple comparisons; $p<0.001$; Fig. $6 A)$. No induction of c-FOS was observed after the SHU9119 hypothermic treatment and no differences were observed between the Ringer's at ZT 2-5 and Ringer's at ZT 18-21 infusions.

In addition, the raphe nucleus was activated after the V1aANT + MTII infusion compared with Ringer's infusion at ZT 2 $\left(F_{(3,8)}=4.947 p=0.03\right.$, multiple comparisons; $p<0.001$; Fig. $6 B)$. There was also a significant increase in c-FOS expression compared with Ringer's infusion after the SHU9119 hypothermic treatment (multiple comparisons, $p<0.05$; Fig. $6 B$ ).

To determine whether the pharmacological treatments in the $\mathrm{MnPO}$ modulate the activity of thermo-effectors in the periphery, we evaluated the effect of V1a-ANT+MTII and SHU9119 on the BAT gene expression. The Upcl gene expression in BAT relative to Ringer's animals was increased in V1a-ANT+MTII treated animals compared with SHU9119-treated animals $\left(t_{(4)}=\right.$ $5.609 p<0.0025$; Fig. 6C). Conversely, rats infused with SHU9119 showed a significant increase in Rev-erb $\alpha$ compared with the animals that received V1Aant + MTII $\left(t_{(4)}=5.309 p<\right.$ 0.003; Fig. 6D), consistent with a decrease in $\mathrm{Tb}$.

\section{Discussion}

The daily rhythm in Tb is set by the SCN (Eastman et al., 1984; Refinetti and Menaker, 1992a), but its amplitude, especially in the transition from dark to light, is influenced by metabolic conditions (Liu et al., 2002; Scheer et al., 2005). Here, we investigated the contribution of the ARC to this phenomena and demonstrated that the $\mathrm{MnPO}$, the main thermoregulatory area in the brain, receives direct projections, not only from the $\mathrm{SCN}$, but also from the ARC, one of the key nuclei involved in the regulation of metabolism.

Previous studies have shown that both AVP (Schwartz et al., 1983; Kalsbeek et al., 1995) and $\alpha$-MSH neurons (Guzmán-Ruiz et al., 2014) have a clear circadian rhythm. Therefore, we chose to 
ZT 2
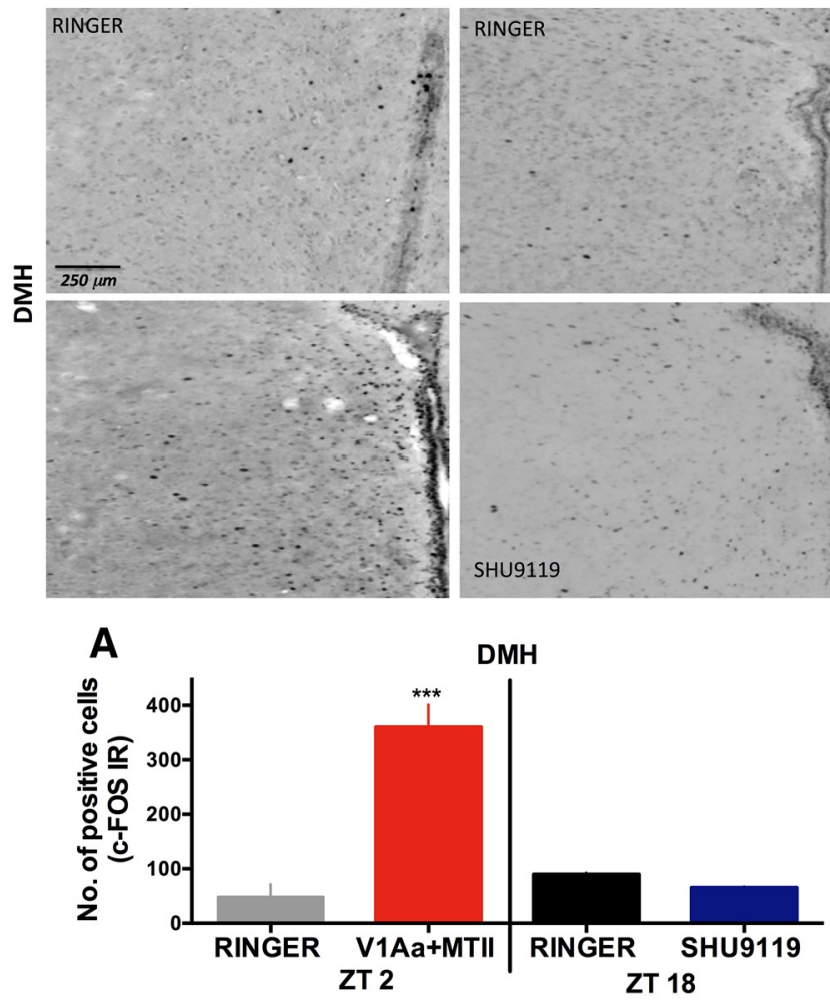

C

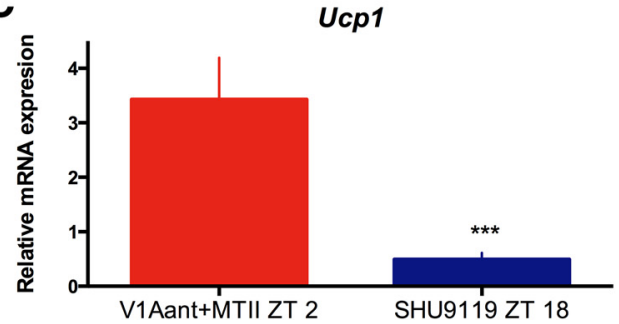

ZT 18

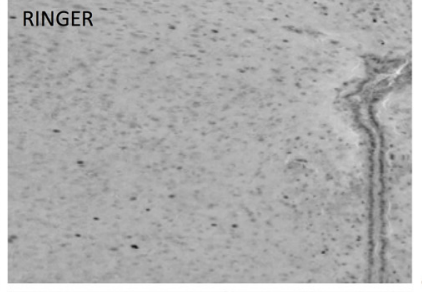

$\frac{2}{\frac{2}{0}}$
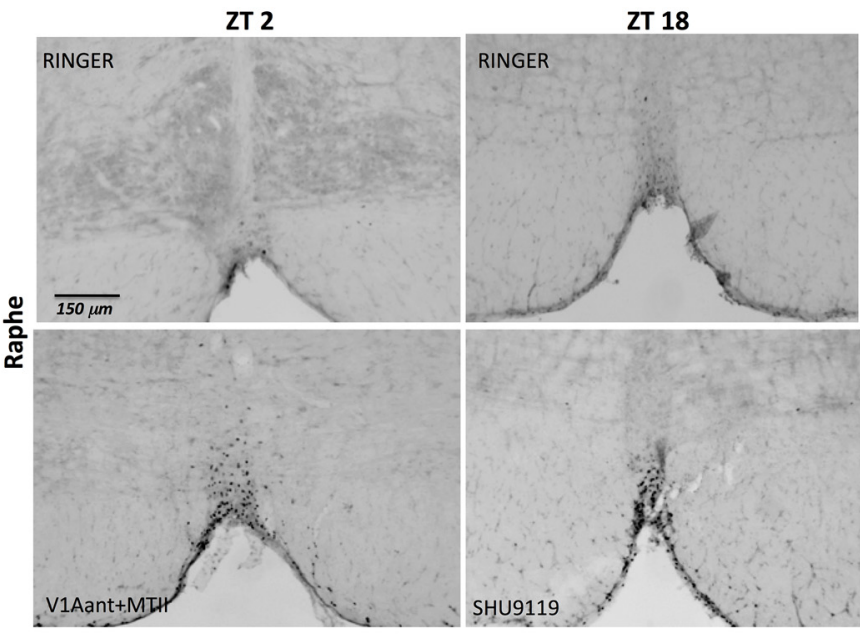

B

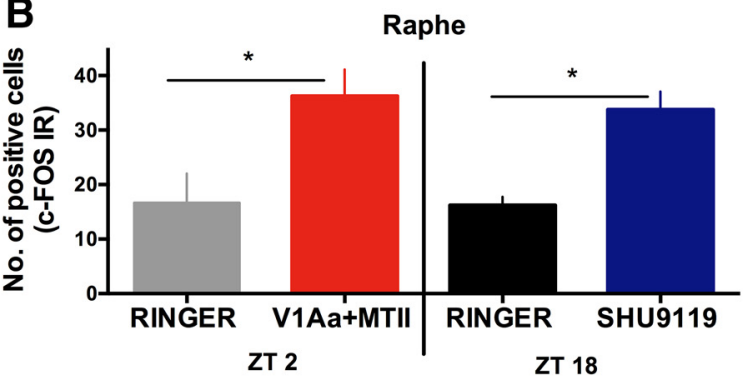

D

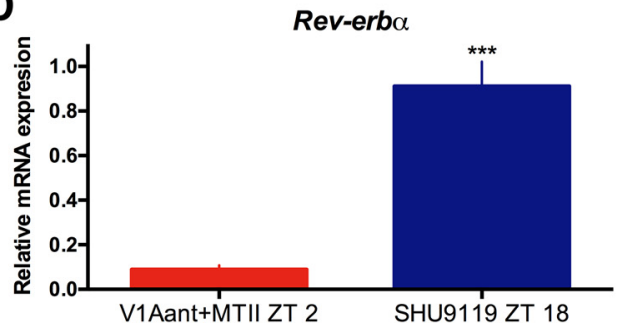

Figure 6. Activation of thermoregulatory pathways. Representative sections of the DMH (left) and the raphe (right) with c-Fos-IR after hypothermic (SHU9119) and hyperthermic (V1aANT + MTII) MD infusions. C-FOS-IR quantification in the DMH ( $\boldsymbol{A})$ and raphe $(\boldsymbol{B})$ after the Ringer's ZT $2(n=3)$, V1a-ANT + MTII $(n=3)$, Ringer's ZT18 $(n=3)$, and SHU9119 ( $n=3)$ infusions. $\boldsymbol{C}$, $D$, BAT Ucp1 (C) and Rev-Erb $\alpha(\boldsymbol{D})$ gene expression relative to their respective Ringer's infusion after the MTII+V1Aant $(n=3)$ and SHU9119 $(n=3)$ infusions. Red bars represent data from hyperthermic infusions and blue bars from hypothermic infusions. Ucp1, Uncoupling protein 1. Results are expressed as mean \pm SEM. Significant differences are indicated. ${ }^{*} p<0.05,{ }^{* * *} p<$ 0.0001 .

investigate the involvement of these two neuropeptides in temperature regulation in the $\mathrm{MnPO}$. The results demonstrate that AVP is involved in the early morning temperature decrease, whereas $\alpha$-MSH is involved in the maintenance of high temperature at night. We also demonstrated that a daily alternation in the AVP and $\alpha-\mathrm{MSH}$ release is essential to precisely time and regulate the drop in temperature at the onset of the light period (Fig. 7). The present observations provide an explanation as to why circadian and metabolic stimuli need to be aligned for the synchronization of physiological processes.

\section{An interaction between the SCN and ARC controls the}

\section{diurnal decrease in temperature}

The present study shows that thermoregulatory activity of the $\mathrm{MnPO}$ is modulated, not only by sensory information from the periphery, but also by the integration of circadian information conveyed by the coordination of the signals from the SCN (AVP) and the ARC ( $\alpha-\mathrm{MSH})$ neurons. The delayed effects of the ago- nist and antagonist infusions suggest that $\mathrm{Tb}$ is determined by rhythmic patterns of AVP and $\alpha$-MSH release.

AVP release from the SCN starts during the late dark period and increases further at the beginning of the light phase (Schwartz et al., 1983). Conversely, we have recently observed an opposite pattern of $\alpha$-MSH neuronal activity with increased c-Fos expression during the dark phase. In addition, we demonstrated that $\alpha$-MSH activity in the dark phase disappears after light exposure (Guzmán-Ruiz et al., 2014). These alternating patterns are in agreement with the temperature changes induced by $\alpha-\mathrm{MSH}$ and AVP antagonists. This demonstrates that the circadian release pattern of AVP and $\alpha$-MSH is related to the diurnal temperature changes (Fig. 7).

$\alpha$-MSH fibers in the hypothalamus originate from the ARC. Even though the POMC neurons in the NTS also express $\alpha$-MSH, their projections only include the lateral parabrachial nucleus and the reticular formation (Fan et al., 2004).

Despite the fact that AVP is found in the SON, BNST, PVN, 


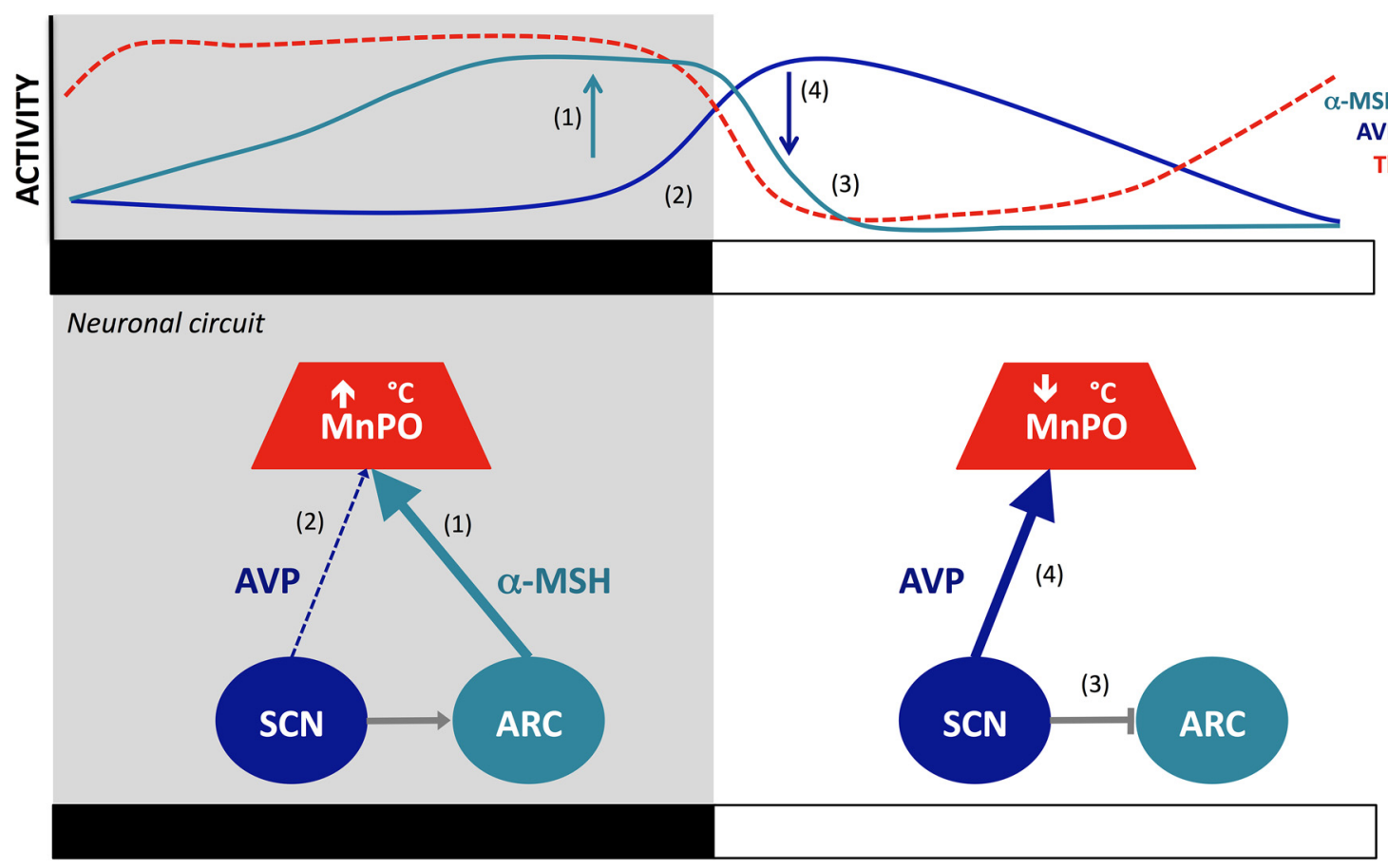

Figure 7. SCN and ARC coordination for diurnal temperature decrease in the MnPO. The MnPO receives SCN and ARC efferents that control the temperature. During the night, an SCN-mediated activation of ARC $\alpha$-MSH (Guzmán-Ruiz et al., 2014) sustains high Tb during the night (1) (Nakamura et al., 2011). In the last part of the dark phase, AVP is released from SCN terminals (2), the hypothermic effects of AVP are counteracted by $\alpha$-MSH activity in the ARC as long as it is night $(1,2)$. At the onset of the light phase, the SCN inhibits the activity of $\alpha$-MSH neurons (3) (Guzmán-Ruiz et al., 2014). Without $\alpha$-MSH thermogenic counteraction, AVP is able to exert its hypothermic effect (4). Top curves illustrate the rhythmic patterns of $\alpha$-MSH activity in the ARC (green), AVP release from the SCN (blue), and Tb (red) modulated at the level of the MnPO. Bottom schemes illustrate the neuronal interaction between the nuclei. Black and white bars indicate the dark and light phases, respectively.

and the SCN, our $\mathrm{CtB}$ injections in the MnPO did not show labeling of the SON and the PVN neurons. In addition, the BNST neurons projecting to the $\mathrm{MnPO}$ were not positive for AVP. This is consistent with previous studies showing that demonstrated that AVP from the BNST does not project to the MPA, because castration in males induces a disappearance of the entire AVP neurons in the BNST and septum without decreasing the AVP fibers present in the entire MPA (de Vries et al., 1986).

Our infusions did not address the question of how the increase in temperature at the end of the resting phase is mediated. A plausible explanation may involve an increase in the $\alpha$-MSH release and the decrease in the AVP release. All of these are observed at the beginning of the dark period.

Another possibility is that the peak in orexin neuronal activity observed during the onset of the activity phase (Yoshimichi et al., 2001; Marston et al., 2008) might be responsible for the temperature increase at the end of the light period. This hypothesis coincides with studies indicating that orexins are able to influence BAT sympathetic activity through projections to the raphe (Berthoud et al., 2005; Madden et al., 2012) and with the fact that orexin A neurons inhibit SCN neuronal activity during the dark phase (Belle et al., 2014).

\section{Tb rhythm is regulated through a preoptic pathway}

The MnPO has well established outputs via DMH and the raphe to modulate peripheral thermo-effectors such as BAT, nonshivering and shivering thermogenesis, and vasomotion (Nakamura, 2011). In the present study, we demonstrated neuronal activation of the $\mathrm{DMH}$ and raphe in response to a thermogenic treatment in the MnPO. The resulting increase of $U c p 1$ expression in BAT after V1a-ANT+MTII demonstrates that at least a part of the thermogenic effect observed in these animals is elicited via the activation of BAT thermogenesis. This increase in Ucp 1 coincides with a decreased expression of Rev-erb $\alpha$, which is in agreement with the knowledge that Rev-erb $\alpha$ is a repressor of Ucp1 in BAT and that its downregulation precedes the physiological induction of Ucp1 (Gerhart-Hines et al., 2013).

Interestingly, the hypothermic SHU9119 infusion did not activate the $\mathrm{DMH}$, in agreement with previous reports indicating that tonic inhibition of the DMH prevents BAT thermogenesis (Tupone et al., 2014). Furthermore, SHU9119 infusion decreased Ucp 1 and increased Rev-erb $\alpha$ expression, which is consistent with the observed Tb decrease (GerhartHines et al., 2013). Finally, activation of Raphe neurons after this hypothermic treatment suggests an enhancement of heat release processes such as tail vasodilatation (Tanaka et al., 2011). In conclusion, the present results indicate that the previously described thermoregulatory pathways are also modulated in a circadian manner.

\section{AVP and $\alpha$-MSH fibers innervate GABAergic neurons in the MnPO}

It is known that the MnPO receives peripheral and central signals to activate both heat release and thermogenic mechanisms. The activation of GABAergic neurons in the MnPO promotes thermogenesis in response to cold, whereas the activation of glutamatergic neurons results in heat loss (Nakamura, 2011; Morrison et al., 2012).

In the present study, we observed that $\alpha$-MSH fibers are in close contact with $65 \%$ of the GABAergic neurons in the MnPO. In addition, $24 \%$ of the GABAergic neurons in the $\mathrm{MnPO}$ are in close contact with AVP fibers. These observa- 
tions, together with the MD data from the MnPO, suggest that the release of $\alpha-\mathrm{MSH}$ to these neurons may induce thermogenesis via BAT activation and that AVP might be inhibitory to the GABAergic inter neurons. We did not detect glutamatergic neurons within the area targeted by our MD experiments, which suggests that the modulation of $\mathrm{Tb}$ is mediated through a GABAergic pathway originating in the MnPO. Further studies are necessary to determine the exact neuronal populations in the MnPO involved in this process.

\section{Consequences of metabolic and temporal desynchronization}

Mammalian endothermy is an expensive adaptation that permits activity of the organism during low ambient temperatures. Therefore, $\mathrm{Tb}$ is tightly regulated in relation to the energy requirements of the individual (i.e., allowing lower Tbs in periods of inactivity). Previous studies have shown that the daily fluctuations in $\mathrm{Tb}$ respond to the metabolic state of the individual and to the signals from the SCN (Refinetti and Menaker, 1992a; Liu et al., 2002; Scheer et al., 2005). Furthermore, in addition to activity (Scheer et al., 2005), daily temperature changes are mainly driven by vasodilatation and BAT thermogenesis (Ootsuka et al., 2009; Gerhart-Hines et al., 2013). Recent studies have demonstrated that BAT thermogenic activity is important for metabolic health because the absence of this tissue induces obesity (Heikens et al., 2011; Vijgen et al., 2011; Vijgen et al., 2012). These observations, together with the present data, emphasize the relevance of a well organized control of BAT thermogenesis.

The development of the endothermy has several advantages. One of them is an ability to sustain activity at low temperatures. The $\mathrm{Tb}$ itself influences the activity of certain enzymes that are responsible for the temporal coordination of metabolic processes (Crompton et al., 1978). This agrees with recent studies proposing that temperature pulses are able to synchronize peripheral oscillators such as in the lung and in the pituitary (Buhr et al., 2010).

The present study shows that the coordination of the SCN and the ARC signals in the $\mathrm{MnPO}$ is essential to control the $\mathrm{Tb}$, BAT thermogenesis, and perhaps other features of physiology.

\section{References}

Belle MD, Hughes AT, Bechtold DA, Cunningham P, Pierucci M, Burdakov D, Piggins HD (2014) Acute suppressive and long-term phase modulation actions of orexin on the mammalian circadian clock. J Neurosci 34:3607-3621. CrossRef Medline

Benstaali C, Mailloux A, Bogdan A, Auzéby A, Touitou Y (2001) Circadian rhythms of body temperature and motor activity in rodents their relationships with the light-dark cycle. Life Sci 68:2645-2656. CrossRef Medline

Berthoud HR, Patterson LM, Sutton GM, Morrison C, Zheng H (2005) Orexin inputs to caudal raphe neurons involved in thermal, cardiovascular, and gastrointestinal regulation. Histochem Cell Biol 123:147-156. CrossRef Medline

Buhr ED, Yoo SH, Takahashi JS (2010) Temperature as a universal resetting cue for mammalian circadian oscillators. Science 330:379-385. CrossRef Medline

Buijs RM, Kalsbeek A (2001) Hypothalamic integration of central and peripheral clocks. Nat Rev Neurosci 2:521-526. CrossRef Medline

Buijs RM, Pool CW, Van Heerikhuize JJ, Sluiter AA, Van der Sluis PJ, Ramkema M, Van der Woude TP, Van der Beek E (1989) Antibodies to small transmitter molecules and peptides: production and application of antibodies to dopamine, serotonin, GABA, vasopressin, vasoactive intestinal peptide, neuropeptide Y, somatostatin and substance P. Biomedical Research 10:213-221.

Clapham JC (2012) Central control of thermogenesis. Neuropharmacology 63:111-123. CrossRef Medline

Cone RD (2005) Anatomy and regulation of the central melanocortin system. Nat Neurosci 8:571-578. CrossRef Medline
Crompton AW, Taylor CR, Jagger JA (1978) Evolution of homeothermy in mammals. Nature 272:333-336. CrossRef Medline

de Vries GJ, Duetz W, Buijs RM, van Heerikhuize J, Vreeburg JT (1986) Effects of androgens and estrogens on the vasopressin and oxytocin innervation of the adult rat brain. Brain Res 399:296-302. CrossRef Medline

Eastman CI, Mistlberger RE, Rechtschaffen A (1984) Suprachiasmatic nuclei lesions eliminate circadian temperature and sleep rhythms in the rat. Physiol Behav 32:357-368. CrossRef Medline

Fan W, Ellacott KL, Halatchev IG, Takahashi K, Yu P, Cone RD (2004) Cholecystokinin-mediated suppression of feeding involves the brainstem melanocortin system. Nat Neurosci 7:335-336. CrossRef Medline

Gerhart-Hines Z, Feng D, Emmett MJ, Everett LJ, Loro E, Briggs ER, Bugge A, Hou C, Ferrara C, Seale P, Pryma DA, Khurana TS, Lazar MA (2013) The nuclear receptor Rev-erbalpha controls circadian thermogenic plasticity. Nature 503:410-413. CrossRef Medline

Guzmán-Ruiz M, Saderi N, Cazarez-Márquez F, Guerrero-Vargas NN, Basualdo MC, Acosta-Galván G, Buijs RM (2014) The suprachiasmatic nucleus changes the daily activity of the arcuate nucleus alpha-MSH neurons in male rats. Endocrinology 155:525-535. CrossRef Medline

Heikens MJ, Gorbach AM, Eden HS, Savastano DM, Chen KY, Skarulis MC, Yanovski JA (2011) Core body temperature in obesity. Am J Clin Nutr 93:963-967. CrossRef Medline

Kalsbeek A, Buijs RM, Engelmann M, Wotjak CT, Landgraf R (1995) In vivo measurement of a diurnal variation in vasopressin release in the rat suprachiasmatic nucleus. Brain Res 682:75-82. CrossRef Medline

LeBlanc J, Soucy J (1996) Interactions between postprandial thermogenesis, sensory stimulation of feeding, and hunger. Am J Physiol 271:R936R940. Medline

Liu S, Chen XM, Yoda T, Nagashima K, Fukuda Y, Kanosue K (2002) Involvement of the suprachiasmatic nucleus in body temperature modulation by food deprivation in rats. Brain Res 929:26-36. CrossRef Medline

Madden CJ, Tupone D, Morrison SF (2012) Orexin modulates brown adipose tissue thermogenesis. Biomol Concepts 3:381-386. Medline

Marston OJ, Williams RH, Canal MM, Samuels RE, Upton N, Piggins HD (2008) Circadian and dark-pulse activation of orexin/hypocretin neurons. Mol Brain 1:19. CrossRef Medline

Morrison SF, Nakamura K, Madden CJ (2008) Central control of thermogenesis in mammals. Exp Physiol 93:773-797. CrossRef Medline

Morrison SF, Madden CJ, Tupone D (2012) Central control of brown adipose tissue thermogenesis. Front Endocrinol (Lausanne) 3.

Nakamura K (2011) Central circuitries for body temperature regulation and fever. Am J Physiol Regul Integr Comp Physiol 301:R1207-R1228. CrossRef Medline

Nakamura K, Morrison SF (2011) Central efferent pathways for colddefensive and febrile shivering. J Physiol 589:3641-3658. CrossRef Medline

Nakamura K, Kawasaki E, Imagawa A, Awata T, Ikegami H, Uchigata Y, Kobayashi T, Shimada A, Nakanishi K, Makino H, Maruyama T, Hanafusa T; Research Committee on Type 1 Diabetes of the Japan Diabetes Society (2011) Type 1 diabetes and interferon therapy: a nationwide survey in Japan. Diabetes Care 34:2084-2089. CrossRef Medline

Ootsuka Y, de Menezes RC, Zaretsky DV, Alimoradian A, Hunt J, Stefanidis A, Oldfield BJ, Blessing WW (2009) Brown adipose tissue thermogenesis heats brain and body as part of the brain-coordinated ultradian basic rest-activity cycle. Neuroscience 164:849-861. CrossRef Medline

Pfaffl MW (2001) A new mathematical model for relative quantification in real-time RT-PCR. Nucleic Acids Res 29:e45. CrossRef Medline

Refinetti R, Menaker M (1992a) The circadian rhythm of body temperature. Physiol Behav 51:613-637. CrossRef Medline

Refinetti R, Menaker M (1992b) Body temperature rhythm of the tree shrew, Tupaia belangeri. J Exp Zool 263:453-457. CrossRef Medline

Romanovsky AA (2007) Thermoregulation: some concepts have changed: functional architecture of the thermoregulatory system. Am J Physiol Regul Integr Comp Physiol 292:R37-R46. Medline

Romon M, Edme JL, Boulenguez C, Lescroart JL, Frimat P (1993) Circadian variation of diet-induced thermogenesis. Am J Clin Nutr 57:476-480. Medline

Saeb-Parsy K, Dyball RE (2003) Responses of cells in the rat suprachiasmatic nucleus in vivo to stimulation of afferent pathways are different at different times of the light/dark cycle. J Neuroendocrinol 15:895-903. CrossRef Medline 
Scheer FA, Pirovano C, Van Someren EJ, Buijs RM (2005) Environmental light and suprachiasmatic nucleus interact in the regulation of body temperature. Neuroscience 132:465-477. CrossRef Medline

Schwartz WJ, Coleman RJ, Reppert SM (1983) A daily vasopressin rhythm in rat cerebrospinal fluid. Brain Res 263:105-112. CrossRef Medline

Seeley RJ, Drazen DL, Clegg DJ (2004) The critical role of the melanocortin system in the control of energy balance. Annu Rev Nutr 24:133-149. CrossRef Medline

Tanaka M, McKinley MJ, McAllen RM (2011) Preoptic-raphe connections for thermoregulatory vasomotor control. J Neurosci 31:5078-5088. CrossRef Medline

Tokizawa K, Uchida Y, Nagashima K (2009) Thermoregulation in the cold changes depending on the time of day and feeding condition: physiological and anatomical analyses of involved circadian mechanisms. Neuroscience 164:1377-1386. CrossRef Medline

Tupone D, Madden CJ, Morrison SF (2014) Autonomic regulation of brown adipose tissue thermogenesis in health and disease: potential clinical applications for altering BAT thermogenesis. Front Neurosci 8:14. Medline

Turek P, Burnett A, Sigman M, Perreault S, Cornwall G, Chau K, Smith J, Prins G, Trasler J, Walsh T, Lamb D (2009) 2008 Annual Meeting of the American Society of Andrology: meeting summary. J Androl 30:e2-e9. CrossRef Medline van den Top M, Spanswick D (2006) Integration of metabolic stimuli in the hypothalamic arcuate nucleus. Prog Brain Res 153:141-154. CrossRef Medline

Vijgen GH, Bouvy ND, Teule GJ, Brans B, Schrauwen P, van Marken Lichtenbelt WD (2011) Brown adipose tissue in morbidly obese subjects. PLoS One 6:e17247. CrossRef Medline

Vijgen GH, Bouvy ND, Teule GJ, Brans B, Hoeks J, Schrauwen P, van Marken Lichtenbelt WD (2012) Increase in brown adipose tissue activity after weight loss in morbidly obese subjects. J Clin Endocrinol Metab 97: E1229-1233. CrossRef Medline

Williams G, Harrold JA, Cutler DJ (2000) The hypothalamus and the regulation of energy homeostasis: lifting the lid on a black box. Proc Nutr Soc 59:385-396. CrossRef Medline

Yi CX, van der Vliet J, Dai J, Yin G, Ru L, Buijs RM (2006) Ventromedial arcuate nucleus communicates peripheral metabolic information to the suprachiasmatic nucleus. Endocrinology 147:283-294. CrossRef Medline

Yoshimichi G, Yoshimatsu H, Masaki T, Sakata T (2001) Orexin-A regulates body temperature in coordination with arousal status. Exp Biol Med (Maywood) 226:468-476. Medline

Zaidi AU, Enomoto H, Milbrandt J, Roth KA (2000) Dual fluorescent in situ hybridization and immunohistochemical detection with tyramide signal amplification. J Histochem Cytochem 48:1369-1375. CrossRef Medline 